\title{
MODEL PREDIKSI BERAT LAHIR BAYI BERDASARKAN FAKTOR- FAKTOR YANG MEMPENGARUHI DI PUSKESMAS KALUKU BODOA TAHUN 2017-2018
}

\section{PREDICTION MODEL OF BIRTH WEIGHT OF INFANTS BASED ON THE FACTORS THAT INFLUENCE IN WORKING AREA OF LOCAL GOVERNMENT CLINIC OF KALUKU BODOA IN 2017-2018}

\author{
Fiola Finandakasih, ${ }^{1}$ Stang Addul Rosmah, ${ }^{2}$ Muhammad Arif Tiro ${ }^{3}$ \\ ${ }^{1}$ Bagian Kesehatan Reproduksi dan Keluarga, Fakultas Kesehatan Masyarakat,Universitas \\ Hasanuddin, \\ ${ }^{2}$ Bagian Biostatistik/KKB Fakultas Kesehatan Masyarakat,Universitas Hasanuddin, \\ ${ }^{3}$ Bagian Ilmu Statistika Fakultas Matematika dan Ilmu Pengetahuan Alam,Universitas Negeri \\ Makassar
}

Alamat Koresponden: Fakultas Kesehatan Masyarakat Universitas Hasanuddin Makassar, 90245, fiolafkmppsunhas@gmail.com

\begin{abstract}
ABSTRAK
Salah satu indikator untuk menentukan derajat kesehatan suatu bangsa ditandai dengan tinggi rendahnya angka kematian ibu dan bayi, target Sustainable Development Goals (SDGs) dalam mengurangi angka kematian neonatal belum tercapai. Berat badan lahir rendah (BBLR) merupakan penyebab utama kematian prenatal. Tujuan penelitian ini untuk mengetahui model prediksi berat lahir bayi berdasarkan faktor-faktor yang mempengaruhi di Puskesmas Kaluku Bodoa tahun 2017-2018. Jenis penelitian ini adalah penelitian retrospektif. Populasi adalah seluruh bayi baru lahir di wilayah kerja Puskesmas Kaluku Bodoa pada bulan Februari tahun 2017 sampai bulan Februari 2018 yang berjumlah 1.223 bayi. Besar sampel adalah 142 bayi diperoleh berdasarkan teknik pengambilan sampel yaitu purposive sampling. Hasil penelitian menunjukkan model prediksi yang diperoleh dari analisis regresi linear berganda yaitu $\boldsymbol{y}=$ $1500,435+2,401 X_{1}+7,446 X_{2}+132,484 X_{3}+128,960 X_{4}+103,877 X_{5}$ dimana $y=$ berat lahir bayi, $X_{1}=$ berat badan ibu sebelum hamil, $X_{2}=$ ukuran LILA, $X_{3}=$ pertambahan berat badan trimester $\mathrm{I}, \mathrm{X}_{4}=$ pertambahan berat badan trimester II, $\mathrm{X}_{5}=$ pertambahan berat badan trimester III $(\mathrm{R} 2=80 \%)$ dan semua asumsi regresi linear terpenuhi.

Kata kunci: Model Prediksi, Retrospektif, Berat Lahir Bayi

\section{ABSTRACT}

One of the indicators for determining the health of a nation characterized by high and low maternal and infant mortality, the target of Sustainable Development Goals (SDGs) in reducing neonatal mortality has not been achieved. Low birth weight $(L B W)$ is a major cause of prenatal mortality. The purpose of this study is to know prediction model of birth weight of infants based on the factors that influence in working area of local government clinic of Kaluku Bodoa in 2017-2018. This study was a retrospective study design. The population is the total number of newborns in working area of local government clinic of Kaluku Bodoa in February 2017 until February 2018, which amounted to 1,223 infants. The sample size was 142 infants obtained by the sampling technique purposive sampling. The results showed the prediction model obtained from multiple linear regression analysis that is $y=1500,435+2,401 X_{1}+7,446 X_{2}+132,484 X_{3}+128,960 X_{4}$

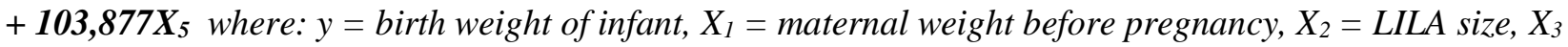
$=$ weight gain in trimester I, $X_{4}=$ weight gain in trimester II, $X_{5}=$ weight gain in trimester III $(R 2=80 \%)$ with all the assumptions of linear regression was fulfilled.
\end{abstract}

Keywords: Prediction Model, Retrospective, Birth Weight of Infant 
PENDAHULUAN

Salah satu indikator untuk menentukan derajat kesehatan suatu bangsa ditandai dengan tinggi rendahnya angka kematian ibu dan bayi. Hal ini merupakan suatu fenomena yang mempunyai pengaruh besar terhadap keberhasilan pembangunan kesehatan. Hal ini selaras dengan tujuan pembangunan Sustainable Development Goals (SDGs) nomor tiga, yaitu menurunkan angka kematian ibu dan bayi pada tahun 2030. Tahun 2016, terjadi 2,6 juta kematian pada periode neonatal, atau sekitar $46 \%$ dari seluruh mortalitas anak di bawah lima tahun, terjadi selama periode ini (Kemenkes RI, 2016).

Berat badan lahir rendah (BBLR) merupakan penyebab utama kematian prenatal (Nursusila, 2017). Sebagian besar bayi dengan BBLR dilahirkan di negara berkembang yaitu 96,5\%, khususnya di daerah yang populasinya rentan. Angka BBLR di Indonesia adalah sekitar 11,1\% pada tahun 2011, termasuk tinggi jika dibandingkan angka BBLR di negara tetangga seperti Vietnam (5,3\%) dan Thailand (6,6\%). Variasi antar provinsi sangat mencolok dari terendah di Sumatera Utara (7,2\%) sampai yang tertinggi di Sulawesi Tengah (16,9\%). Provinsi Sulawesi Selatan menempati peringkat tujuh tertinggi terjadinya prevalensi BBLR yaitu $12 \%$ (Kemenkes RI, 2016). Pada tahun 2015, persentase bayi dengan BBLR di Sulawesi Selatan meningkat yaitu 4.697 kasus $(3,23 \%)$, dengan jumlah lahir hidup sebesar 149.986 dan jumlah bayi lahir hidup ditimbang sebesar 120.293 dan tertinggi di Kota Makassar sebesar 690 kasus (Dinkes Sulsel, 2015). Berdasarkan data profil kesehatan kota Makassar tahun 2015, angka kejadian BBLR tertinggi terdapat di Puskesmas Kaluku Bodoa yaitu berjumlah 121 kasus $(9,46 \%)$ dari 1.279 kelahiran hidup (Dinkes Kota Makassar, 2016).

Berat badan ibu sebelum hamil yang merupakan gambaran status gizi ibu, memiliki hubungan erat dengan berat lahir bayi, dimana ibu yang kurus atau malnutrisi melahirkan bayi berat lahir rendah (Kumar, 2010). Salah satu cara untuk menilai status gizi ibu selama kehamilan melalui pemeriksaan antropometrik, yang dapat dilakukan dengan mengukur berat badan ibu sebelum hamil, tinggi badan, indeks massa tubuh, dan lingkar lengan atas (LILA). Kenaikan berat badan selama kehamilan merupakan gambaran laju pertumbuhan janin dalam kandungan yang perlu diperhatikan karena kenaikan berat badan yang kurang bisa menimbulkan permasalahan yang serius bagi bayi dan ibunya. Ibu yang kurus 
cenderung menghasilkan BBLR dengan dampak yang ditimbulkannya (Ferial, 2011).

Keadaan gizi Ibu hamil dipengaruhi langsung oleh status gizi ibu sebelum hamil dan asupan makanan yang dikonsumsi selama kehamilan serta banyak faktor secara tidak langsung antara lain demografi seperti umur, pekerjaan, pendidikan, pendapatan, karakteristik ibu seperti kebiasaan merokok, tinggi badan, jarak kelahiran, status ANC. Memperhatikan faktor faktor tersebut mendukung intervensi dalam memantau kesehatan ibu hamil yang di tandai pertambahan berat badan ibu yang akan memengaruhi berat bayi lahir (Setiati dkk., 2017). Studi di Jawa Tengah pada tahun 2010 oleh Budiman menunjukkan adanya korelasi positif dan kuat antara berat badan ibu hamil, umur, paritas, tinggi badan dengan berat lahir dan faktor yang paling menentukan adalah berat badan ibu hamil dan umur (Budiman, 2010).

Penelitian ini bertujuan mendapatkan model untuk memprediksi berat lahir berdasarkan faktor yang berpengaruh terhadap berat lahir bayi di Puskesmas Kaluku Bodoa tahun 2017-2018.

\section{BAHAN DAN METODE}

\section{Lokasi dan Rancangan Penelitian}

Penelitian ini dilaksanakan pada posyandu di wilayah kerja Puskesmas Kaluku
Bodoa Kota Makassar. Desain studi yang digunakan dalam penelitian ini adalah studi retrospektif.

\section{Populasi dan Sampel}

Populasi kasus dalam penelitian ini adalah seluruh bayi baru lahir yang tercacat dalam data bulanan posyandu pada Februari tahun 2017 sampai bulan Februari tahun 2018 yang berjumlah 1.223 bayi. Sampel sebanyak 142 orang yang dipilih dengan teknik purposive sampling yang telah memenuhi kriteria inklusi yaitu ibu yang melakukan kunjungan di posyandu, bayi yang lahir pada Februari 2017 - Februari 2018, ibu yang masih mengingat berat badan ibu sebelum hamil dalam waktu satu tahun sebelum hamil, memiliki buku KMS/ KIA, memiliki data lengkap ANC selama hamil dan ibu bertempat tinggal di wilayah kerja Puskesmas Kaluku Bodoa.

\section{Metode Pengumpulan Data}

Instrumen atau alat pengumpulan data dalam penelitian ini adalah menggunakan pedoman dokumentasi, wawancara (data primer) dan pencatatan data sekunder. Instrumen ini bermanfaat untuk mengumpulkan data yang meliputi usia ibu, lama pendidikan, jumlah kunjungan ANC, konsumsi tablet $\mathrm{Fe}$, paparan asap rokok, jarak kelahiran, jumlah paritas, riwayat abortus, ukuran LILA, berat badan ibu sebelum hamil, 
pertambahan berat badan Trimester I, pertambahan berat badan Trimester II, pertambahan berat badan Trimester III terhadap berat lahir bayi di wilayah kerja Puskesmas Kaluku Bodoa Tahun 2017-2018. Data primer berupa data yang tidak terdapat dan tidak tercakup dalam buku KIA/KMS yang berisi data catatan kesehatan ibu hamil, kunjungan ANC ibu selama hamil, dan data berat lahir anak yang diperoleh pada saat posyandu di wilayah kerja Puskesmas Kaluku Bodoa. Data-data tersebut diperoleh dengan menanyakan secara langsung kepada responden dengan wawancara langsung. Data sekunder berupa data angka kematian bayi (AKB), Cakupan Antenatal Terpadu, angka kejadian BBLR di Dinas Kesehatan Kota Makassar dan data jumlah bayi lahir hidup, kunjungan ANC, dan kejadian BBLR di Puskesmas Kaluku Bodoa serta data yang berasal dari buku KIA/KMS yang berisi data catatan kesehatan ibu hamil, kunjungan ANC ibu selama hamil, dan data berat lahir anak yang diperoleh pada saat posyandu di wilayah kerja Puskesmas Kaluku Bodoa.

\section{Analisis Data}

Menentukan penyajian data dan uji hipotesis yang akan digunakan, dilakukan uji normalitas untuk melihat suatu data memiliki distribusi normal atau tidak. Uji normalitas yang digunakan adalah uji normalitas secara analitik yakni uji Kolmogorov-Smirnov untuk sampel yang berjumlah lebih dari 50 . Pelaporan deskriptif variabel bergantung pada sebaran data. Bila sebaran data normal, digunakan rerata dan simpang baku sebagai ukuran pemusatan dan penyebaran. Bila tidak normal, digunakan median dan persentil sebagai ukuran pemusatan dan penyebaran. Pada variabel yang menggunakan skala kategori yaitu konsumsi tablet Fe dan paparan asap rokok digunakan distribusi frekuensi untuk memberikan gambaran deskriptif masing-masing variabel.

Analisis statistik yang digunakan adalah uji korelasi Pearson yang dinyatakan dengan koefisien korelasi (r) yaitu untuk menjawab apakah terdapat korelasi antara variabel independen dan dependen, ke mana arah hubungannya, dan seberapa besar derajat hubungannya, sementara variabel yang bersifat kategorik seperti konsumsi tablet Fe dan paparan asap rokok menggunakan uji $\mathrm{t}$ tidak berpasangan. Penggunaan analisis tersebut didasarkan pada jenis penelitian ini adalah analitik korelatif numerik-numerik dan analitik korelatif numerik-nominal dengan asumsi uji yakni skala pengukurannya numerik serta paling tidak salah satu variabel terdistribusi normal dan linearitas terpenuhi. Sementara uji alternatifnya adalah uji Spearman (Stang, 
2014).

Analisis Multivariat digunakan untuk membuat model prediksi berat lahir bayi berdasarkan usia ibu, lama pendidikan, jumlah kunjungan ANC, konsumsi tablet Fe, paparan asap rokok, jarak kelahiran, jumlah paritas, riwayat abortus, ukuran LILA, berat badan ibu sebelum hamil, pertambahan berat badan Trimester I, pertambahan berat badan Trimester II, pertambahan berat badan Trimester III di wilayah kerja Puskesmas Kaluku Bodoa tahun 2017-2018.

Model yang dihasilkan didasarkan dari mengidentifikasi faktor yang dominan berpengaruh antara variabel terikat berat lahir bayi dengan seluruh variabel bebas yang diteliti menggunakan uji regresi linear (Singh dkk., 2014). Regresi linear digunakan apabila hendak mengetahui hubungan satu variabel terikat yang mempunyai skala pengukuran numerik dengan satu atau lebih variabel bebas. Keluaran regresi linear yang paling penting adalah persamaan regresi. Persamaan regresi linear secara lengkap adalah sebagai berikut : $y=a+b_{1} x_{1}+b_{2} x_{2}+b_{3} x_{3}+\ldots \ldots \ldots+$ $b_{n} x_{n}+\varepsilon$.

\section{HASIL}

\section{Uji Normalitas}

Hasil penenlitian ini untuk menentukan penyajian deskriptif data dan uji hipotesis yang akan digunakan, maka dilakukan uji normalitas terlebih dahulu untuk melihat suatu data memiliki distribusi normal atau tidak. Sehingga variabel yang terdistribusi normal dengan nilai $p>0,05$ maka penyajian data menggunakan nilai rerata (mean), simpangan baku, dan interval kepercayaan. Variabel yang tidak terdistribusi normal dengan nilai $\mathrm{p}<0,05$ maka penyajian data menggunakan nilai median, nilai maksimun, dan minimum. Selanjutnya untuk melihat analisis korelasi antara variabel penelitian maka dilakukan uji korelasi Pearson yang dinyatakan dengan koefisien korelasi (r) yaitu untuk melihat adanya korelasi, ke mana arah hubungannya, dan seberapa besar derajat hubungannya dalam variabel penelitian. Namun, dengan syarat yakni skala pengukurannya numerik serta paling tidak salah satu variabel terdistribusi normal dan linearitas terpenuhi Sedangkan uji alternatifnya adalah Uji Korelasi Spearman (Tiro, 2010).

Tabel 1 menjelaskan bahwa variable yang memiliki distribusi data normal yaitu berat lahir bayi, umur ibu dan berat badan ibu sebelum hamil dengan nilai $\mathrm{p}>0,05$. Sementara variabel yang memiliki distribusi data tidak normal yaitu lama pendidikan ibu, jarak kelahiran, paritas, riwayat abortus, 
LILA, pertambahan berat badan trimester I, pertambahan berat badan trimester II, pertambahan berat badan trimester III dengan nilai $\mathrm{p}<0,05$.

Tabel 1. Hasil Uji Normalitas Data

\begin{tabular}{cccc}
\hline \multirow{2}{*}{ Variabel } & \multicolumn{3}{c}{ Uji Normalitas Kolmogorov-Smirnov } \\
\cline { 2 - 4 } & Signifikansi (p) & Jumlah (n) & Keterangan \\
\hline Berat Lahir Bayi & 0,082 & 142 & Normal \\
Umur Ibu & 0,386 & 142 & Normal \\
Lama Pendidikan Ibu & $<0,001$ & 142 & Tidak Normal \\
Jarak Kelahiran & 0,003 & 142 & Tidak Normal \\
Paritas & $<0,001$ & 142 & Tidak Normal \\
Jumlah Kunjungan ANC & $<0,001$ & 142 & Tidak Normal \\
Riwayat Abortus & $<0,001$ & 142 & Tidak Normal \\
Ukuran LILA & 0,035 & 142 & Tidak Normal \\
Paparan Asap Rokok & $<0,001$ & 142 & Tidak Normal \\
Konsumsi Tablet Fe & $<0,001$ & 142 & Tidak Normal \\
Berat Badan Ibu Sebelum Hamil & 0,061 & 142 & Normal \\
Pertambahan Berat Badan Trimester I & $<0,001$ & 142 & Tidak Normal \\
Pertambahan Berat Badan Trimester II & $<0,001$ & 142 & Tidak Normal \\
Pertambahan Berat Badan Trimester III & 0,001 & 142 & Tidak Normal \\
\hline Sumbertak
\end{tabular}

Sumber: Data Primer, 2018

\section{Analisis Deskriptif Variabel Penelitian}

Tabel 2 dideskripsikan bahwa ratarata berat lahir bayi per individu adalah sebesar 2960 gram, rata-rata umur ibu per individu adalah 28 tahun, kisaran lama pendidikan ibu adalah 9 tahun yang berarti lulus di tingkat Sekolah Menengah Pertama, dengan lama pendidikan ibu terendah adalah 6 tahun (SD) dan tertinggi 16 tahun (Perguruan Tinggi), kisaran jumlah paritas adalah 2 kali, dengan jumlah paritas terendah adalah 1 kali dan tertinggi 7 kali melahirkan, kisaran jarak kelahiran adalah 3 tahun dengan jarak kelahiran paling dekat yaitu 0 tahun dan paling jauh yaitu 17 tahun, kisaran kunjungan
ANC adalah 4 kali dengan kunjungan ANC terendah yaitu 3 kali dan tertinggi yaitu 4 kali, kisaran riwayat abortus adalah tidak pernah memiliki riwayat abortus sampai tertinggi memiliki riwayat abortus sebanyak 7 kali, kisaran ukuran LILA adalah $25 \mathrm{~cm}$ dengan LILA minimum dan maksimum adalah 18 sampai $39 \mathrm{~cm}$, rata-rata berat badan ibu sebelum hamil per individu adalah $53 \mathrm{~kg}$, kisaran pertambahan berat badan ibu hamil trimester I adalah sebesar $1 \mathrm{~kg}$ dengan penurunan berat badan ibu hamil trimester I sebesar $5 \mathrm{~kg}(-5 \mathrm{~kg})$ dan peningkatan berat badan ibu trimester I sebesar $3 \mathrm{~kg}$, kisaran pertambahan berat badan ibu hamil trimester 
II adalah sebesar $3 \mathrm{~kg}$ dengan peningkatan berat badan ibu hamil trimester II yang terendah sebesar $1 \mathrm{~kg}$ dan tertinggi sebesar 6 $\mathrm{kg}$ dan kisaran pertambahan berat badan ibu hamil trimester III adalah sebesar $5 \mathrm{~kg}$ dengan peningkatan berat badan ibu hamil trimester III terendah sebesar $2 \mathrm{~kg}$ dan tertinggi sebesar
Tabel 3, dideskripsikan bahwa dari 142 responden, tertinggi pada responden yang terpapar asap rokok sebanyak 101 (71,1\%) dan dideskripsikan bahwa dari 142 responden, tertinggi pada responden yang tidak mengonsumsi tablet $\mathrm{Fe}$ sebanyak 97 $(68,3 \%)$.

$9 \mathrm{~kg}$.

Tabel 2. Penyajian Deksriptif berdasarkan Faktor-Faktor yang Mempengaruhi di Wilayah Kerja Puskesmas Kaluku Bodoa Tahun 2017-2018

\begin{tabular}{|c|c|c|}
\hline Variabel & Rerata (s.b) & Interval Kepercayaan (95\%) \\
\hline Berat Lahir Bayi & $2958,80(418,216)$ & $2889,42-3028,18$ \\
\hline Umur Ibu & $28,24(6,437)$ & $27,17-29,31$ \\
\hline Variabel & \multicolumn{2}{|c|}{ Median (Minimum - Maksimum) } \\
\hline Pendidikan Ibu & \multicolumn{2}{|c|}{$9,00(6-16)$} \\
\hline Paritas & \multicolumn{2}{|c|}{$2,00(1-7)$} \\
\hline Jarak Kelahiran & \multicolumn{2}{|c|}{$3,00(0-17)$} \\
\hline Jumlah Kunjungan $A N C$ & \multicolumn{2}{|c|}{$4,00(3-4)$} \\
\hline Riwayat Abortus & \multicolumn{2}{|c|}{$0,00(0-7)$} \\
\hline LILA & \multicolumn{2}{|c|}{$25,00(18-39)$} \\
\hline Variabel & Rerata (s.b) & Interval Kepercayaan (95\%) \\
\hline $\begin{array}{c}\text { Berat Badan Ibu Sebelum } \\
\text { Hamil }\end{array}$ & $53,08(10,925)$ & $51,27-54,89$ \\
\hline Variabel & \multicolumn{2}{|c|}{ Median (Minimum - Maksimum) } \\
\hline $\begin{array}{c}\text { Pertambahan Berat } \\
\text { Badan Trimester I }\end{array}$ & \multicolumn{2}{|c|}{$1,00(-5-3)$} \\
\hline $\begin{array}{l}\text { Pertambahan Berat } \\
\text { Badan Trimester II }\end{array}$ & \multicolumn{2}{|c|}{$3,00(1-6)$} \\
\hline $\begin{array}{l}\text { Pertambahan Berat } \\
\text { Badan Trimester III }\end{array}$ & \multicolumn{2}{|c|}{$5,00(2-9)$} \\
\hline
\end{tabular}

Tabel 3. Penyajian Deksriptif berdasarkan Faktor-Faktor yang Mempengaruhi di Wilayah Kerja Puskesmas Kaluku Bodoa Tahun 2017-2018

\begin{tabular}{ccc}
\hline Paparan Asap Rokok & $\mathbf{n}$ & $\mathbf{\%}$ \\
\hline Terpapar & 101 & 71,1 \\
Tidak Terpapar & 41 & 28,9 \\
\hline Jumlah & $\mathbf{1 4 2}$ & $\mathbf{1 0 0 , 0}$ \\
\hline Konsumsi Tablet Fe & $\mathbf{n}$ & $\mathbf{\%}$ \\
\hline Mengonsumsi & 45 & 31,7 \\
Tidak Mengonsumsi & 97 & 68,3 \\
\hline Jumlah & $\mathbf{1 4 2}$ & $\mathbf{1 0 0 , 0}$ \\
\hline
\end{tabular}


Finandakasih, 2019

Korelasi antara Variabel Independen dengan Berat Lahir Bayi

Tabel 4 menunjukkan korelasi antara umur ibu, pendidikan ibu, jumlah paritas, jarak kelahiran, jumlah kunjungan ANC,riwayat abortus, paparan asap rokok dan konsumsi tablet Fe dengan berat lahir bayi di wilayah kerja Puskesmas Kaluku Bodoa tahun 2017-2018 dinyatakan tidak

Tabel 4. Hasil Analisis Korelasi Faktor-Faktor yang Mempengauhi Berat Lahir Bayi di Wilayah Kerja Puskesmas Kaluku Bodoa Tahun 2017-2018

\begin{tabular}{lc}
\hline \multicolumn{1}{c}{ Variabel } & p value \\
\hline Umur Ibu & 0,402 \\
Pendidikan Ibu & 0,351 \\
Paritas & 0,511 \\
Jarak Kelahiran & 0,905 \\
Jumlah Kunjungan ANC & 0,888 \\
Riwayat Abortus & 0,477 \\
LILA & 0,001 \\
Paparan Asap Rokok & 0,484 \\
Konsumsi Tablet Fe & 0,137 \\
Berat Badan Ibu Sebelum Hamil & $<0,001$ \\
Pertambahan Berat Badan Trimester I & $<0,001$ \\
Pertambahan Berat Badan Trimester II & $<0,001$ \\
Pertambahan Berat Badan Trimester III & $<0,001$ \\
\hline
\end{tabular}

Tabel 5. Analisis Multivariat Model Prediksi Berat Lahir Bayi Berdasarkan Faktor-Faktor Yang Mempengaruhi di Wilayah Kerja Puskesmas Kaluku Bodoa Tahun 20172018

\begin{tabular}{cccccc}
\hline Model & $\begin{array}{c}\text { Koefisien } \\
\text { Tidak Standar }\end{array}$ & $\begin{array}{c}\text { Std. } \\
\text { Error }\end{array}$ & $\begin{array}{c}\text { Koefisien } \\
\text { Korelasi }\end{array}$ & T & Nilai $\boldsymbol{p}$ \\
\hline Interseps & 1500,435 & 127,725 & & 11,747 & $<0,001$ \\
Ukuran LILA & 7,446 & 7,863 & 0,065 & 0,947 & 0,345 \\
BB sebelum hamil & 2,401 & 2,718 & 0,063 & 0,884 & 0,378 \\
Pertambahan BB & 132,484 & 13,067 & 0,445 & 10,139 & $<0,001$ \\
$\quad$ Trimester I & 128,960 & 19,391 & 0,350 & 6,650 & $<0,001$ \\
$\begin{array}{c}\text { Pertambahan BB } \\
\text { Trimester II }\end{array}$ & 103,877 & 13,591 & 0,344 & 7,643 & $<0,001$ \\
$\begin{array}{c}\text { Pertambahan BB } \\
\text { Trimester III }\end{array}$ & & & & & \\
\hline
\end{tabular}


tahap analisis dimasukkan variabel

\section{Model Prediksi Berat Lahir Bayi}

Membuat model prediksi berat lahir bayi berdasarkan faktor-faktor yang mempengaruhi di wilayah kerja Puskesmas Kaluku Bodoa Tahun 2017-2018 yaitu dengan menggunakan analisis regresi linear berganda. Syarat dalam analisis regresi linear berganda yaitu variabel yang mempunyai nilai $\mathrm{p}<0,25$. Sehingga, variabel independen yang bisa di masukkan dalam model analisisregresi linear berganda yaitu variabel dari hasil uji korelasi yang mempunyai nilai $\mathrm{p}<0,25$ (Stang, 2017). Tabel 4 menunjukkan variabel umur ibu, pendidikan ibu, jarak kelahiran, paritas, jumlah kunjungan ANC, riwayat abortus mempunyai nilai $p>0,25$, sedangkan variabel paparan asap rokok dan konsumsi tablet Fe tidak memenuhi syarat analisis regresi linier karena skala pengukurannya bersifat kategorik. Sehingga variabel-variabel tersebut tidak diikutsertakan dalam tahapan analisis multivariat selanjutnya karena variabel tersebut adalah variabel yang paling layak dikeluarkan karena tidak memenuhi syarat untuk dimasukkan dalam model analisis regresi linear.

Tabel 5 menunjukkan hasil tahapan dari analisis regresi linear berganda. Pada independen yaitu ukuran LILA, berat badan ibu sebelum hamil, pertambahan berat badan trimester I, II dan III. Namun dari proses analisis, variabel berat badan ibu sebelum hamil dan ukuran LILA diduga menjadi variabel confounding karena memiliki nilai p>0,05 maka dari itu diperlukan analisis uji konfounding. Jika variabel tersebut adalah bukan konfounding,maka harus dikeluarkan dari pemodelan multivariat. Namun, jika variabel tersebut adalah konfounding,maka harus dimasukkan kembali ke dalam pemodelan multivariat (Nelson dkk., 2011).

Variabel yang dicurigai merupakan konfounding yaitu varibel berat badan ibu sebelum hamil dan ukuran LILA. Dalam analisis multivariat, terjadi perubahan nilai koefisien b yang lebih dari 10\% yaitu variabel ukuran LILA dan variabel berat badan ibu sebelum hamil merupakan konfounding, jadi tidak bisa dikeluarkan dari pemodelan multivariat.

Sehingga diperoleh persamaan regresi linear yakni $y=1500,435+2,401 X_{1}+$ $7,446 X_{2}+132,484 X_{3}+128,960 X_{4}+$ 103,877X $X_{5}$ dimana $: \mathrm{y}=$ berat lahir bayi, $\mathrm{X}_{1}=$ berat badan ibu sebelum hamil, $\mathrm{X}_{2}=$ ukuran LILA, $\quad \mathrm{X}_{3}=$ pertambahan berat badan trimester $\mathrm{I}, \mathrm{X}_{4}=$ pertambahan berat badan trimester II, $\mathrm{X}_{5}=$ pertambahan berat badan 
Finandakasih, 2019

trimester III $\left(\mathrm{R}^{2}=80 \%\right)$. Semua asumsi

regresi linear yaitu linearitas, normalitas, 
multikolinieritas, autokorelasi dan homoskedatisitas terpenuhi.

\section{PEMBAHASAN}

Dalam penelitian ini terlihat bahwa ada pengaruh ukuran LILA, berat badan ibu sebelum hamil, pertambahan berat badan Trimester I, pertambahan berat badan Trimester II, pertambahan berat badan Trimester III dengan berat lahir bayi di Puskesmas Kaluku Bodoa tahun 2017-2018. Persamaan yang diperoleh untuk membuat model prediksi adalah $y=1500,435+$ $2,401 X_{1}+7,446 X_{2}+132,484 X_{3}+128,960 X_{4}$ $+103,877 X_{5}$ dimana $: \mathrm{y}=$ berat lahir bayi, $\mathrm{X}_{1}$ $=$ berat badan ibu sebelum hamil, $\mathrm{X}_{2}=$ ukuran LILA, $\quad X_{3}=$ pertambahan berat badan trimester $\mathrm{I}, \mathrm{X}_{4}=$ pertambahan berat badan trimester II, $\mathrm{X}_{5}=$ pertambahan berat badan trimester III $\left(\mathrm{R}_{2}=80 \%\right)$.

Ukuran LILA tiap individu di wilayah kerja Puskesmas Kaluku Bodoa tahun 20172018 adalah tertinggi $39 \mathrm{~cm}$ dan terendah 18 cm dari hasil uji korelasi Pearson, diperoleh nilai $\mathrm{p}=0,001<0,05$, maka korelasi antara ukuran LILA dengan berat lahir bayi di wilayah kerja Puskesmas Kaluku Bodoa tahun 2017-2018 dinyatakan bermakna. Penelitian ini sejalan dengan penelitian Muqsith (2015) yang menyatakan ada hubungan antara LILA dengan berat lahir bayi. Lingkar lengan atas merupakan indikator status gizi yang digunakan terutama untuk deteksi kurang energi protein pada anak-anak dan merupakan indikator yang baik untuk mendeteksi wanita usia subur dan ibu hamil dengan risiko melahirkan bayi dengan berat badan lahir rendah. Pengukuran LILA lebih baik untuk menilai status gizi ibu hamil, karena pada wanita hamil dengan malnutrisi (gizi kurang atau lebih) kadangkadang menunjukkan edema tetapi ini jarang mengenai lengan atas. Kurang energi kronis (KEK) adalah suatu kondisi kurang gizi disebabkan rendahnya konsumsi energi dalam makanan sehari-hari yang berlangsung menahun sehingga tidak memenuhi angka kecukupan gizi (Kumar, 2010).

Kisaran berat badan ibu sebelum hamil tiap individu di wilayah kerja Puskesmas Kaluku Bodoa tahun 2017-2018 adalah $53 \mathrm{~kg}$, dari hasil uji korelasi Pearson, diperoleh nilai nilai $\mathrm{p}=<0,001<0,05$, maka korelasi antara berat badan ibu sebelum hamil dengan berat lahir bayi di wilayah kerja Puskesmas Kaluku Bodoa tahun 2017-2018 dinyatakan bermakna. Penelitian ini juga sejalan dengan penelitian Patki (2017) yang mengemukakan bahwa status gizi ibu sebelum dan selama hamil dapat mempengaruhi pertumbuhan janin yang sedang dikandung. Berat badan ibu sebelum 
kehamilan merupakan salah satu faktor yang penting dalam menentukan perkembangan dan kesehatan janin yang dapat dilihat dari berat lahir bayi. Ibu yang memiliki berat badan yang normal sebelum kehamilan lebih memiliki kemampuan mempersiapkan dan memberikan asupan makan yang cukup kepada janinnya di awal kehamilan (Frederick dkk., 2008).

Kisaran pertambahan berat badan trimester I tiap individu di wilayah kerja Puskesmas Kaluku Bodoa tahun 2017-2018 adalah $1 \mathrm{~kg}$ dengan terjadi penurunan berat badan ibu hamil saat trimester I sebesar $5 \mathrm{~kg}$ $(-5 \mathrm{~kg})$ dan terjadi peningkatan berat badan ibu saat trimester I tertinggi sebesar $3 \mathrm{~kg}$. Dari hasil uji korelasi Pearson, diperoleh nilai $\mathrm{p}=$ $<0,001<0,05$, maka terdapat korelasi yang bermakna antara pertambahan berat badan trimester I dengan berat lahir bayi di wilayah kerja Puskesmas Kaluku Bodoa tahun 2017 2018. Hasil analisis sesusai dengan penelitian Brown (2005) bahwa janin yang mengalami kekurangan gizi sejak trimester I akan mengalami penurunan regulasi pertumbuhan, berat lahir rendah dengan proporsi tubuh yang kecil. Kenaikan berat badan yang rendah pada trimester I akan menyebabkan bayi lahir bayi dengan berat badan rendah. Pertambahan berat badan trimester I dapat dianggap sebagai berat badan ibu sebelum hamil karena selama trimester I pertambahan berat badan tidak bermakna. Penambahan berat badan ibu semasa kehamilan menggambarkan laju pertumbuhan janin dalam kandungan. Pada usia kehamilan trimester satu laju pertambahan berat badan ibu belum tampak nyata karena pertumbuhan janin belum pesat, tetapi memasuki usia kehamilan trimester dua laju pertumbuhan janin mulai pesat dan pertambahan berat badan ibu juga mulai pesat (Heerman dkk., 2014).

Kisaran pertambahan berat badan trimester II tiap individu di wilayah kerja Puskesmas Kaluku Bodoa tahun 2017-2018 adalah $3 \mathrm{~kg}$ dengan peningkatan berat badan ibu hamil saat trimester II adalah tertinggi sebesar $6 \mathrm{~kg}$ dan terendah sebesar $1 \mathrm{~kg}$. Hasil uji korelasi Pearson, diperoleh nilai $\mathrm{p}=<$ $0,001<0,05$, maka terdapat korelasi yang bermakna antara pertambahan berat badan trimester II dengan berat lahir bayi di wilayah kerja Puskesmas Kaluku Bodoa tahun 2017 2018. Penelitian ini sejalan dengan penelitian Sari (2013), hasil uji statistik didapatkan ada hubungan yang signifikan antara pertambahan berat badan trimester II dengan berat lahir. Kenaikan berat badan rata-rata yang ideal pada masa ini adalah 0,35 sampai $0,4 \mathrm{~kg}$ per minggu. 
Sebesar $60 \%$ kenaikan berat badan ini dikarenakan pertumbuhan jaringan pada ibu.

Kenaikan berat badan akan lebih baik bila terjadi secara perlahan dan kontinyu (Maddah dkk., 2005). Penelitian Davis (2014) yang menyatakan bahwa janin yang kekurangan zat gizi pada trimester II dapat mengakibatkan gangguan hubungan fetoplasenta, bayi lahir dengan berat badan kurang dan proporsi tubuh kurus.

Kisaran pertambahan berat badan trimester III tiap individu di wilayah kerja Puskesmas Kaluku Bodoa tahun 2017-2018 adalah $5 \mathrm{~kg}$ dengan peningkatan berat badan ibu hamil saat trimester III adalah tertinggi sebesar $9 \mathrm{~kg}$ dan terendah sebesar $2 \mathrm{~kg}$. Hasil uji korelasi Pearson, diperoleh nilai $\mathrm{p}=0,001$ $<0,05$, maka terdapat korelasi yang bermakna antara pertambahan berat badan trimester III dengan berat lahir bayi di wilayah kerja Puskesmas Kaluku Bodoa tahun 2017 - 2018. Penelitian ini sejalan dengan hasil penelitian Sari (2013) menyatakan pertambahan berat badan pada trimester III memiliki hubungan dengan berat lahir, dan memiliki hubungan yang sedang dan berpola positif. Pada trimester III, pertambahan berat badan ibu hamil meningkat lebih drastis. Pertambahan berat badan yang meningkat drastis dikarenakan janin semakin pesat, dimana $60 \%$ dari pertambahan berat badan merupakan bagian dari janin (Karima, 2012). Apabila status gizi ibu buruk, baik sebelum kehamilan dan selama kehamilan akan menyebabkan Berat Badan Lahir Rendah (BBLR). Kurangnya suplai gizi yang ditandai dengan rendahnya pertambahan berat badan trimester III menyebabkan penyelamatan pertumbuhan otak melalui pengalihan aliran darah untuk menyuplai zat gizi ke otak, dengan menomorduakan pertumbuhan badan. Hal ini dapat mengakibatkan kurang berkembangnya hati, dan produk terkaitnya. Dampaknya meliputi gangguan mengendalikan kadar kolestrol darah, dan faktor pembekuan darah, dan meningkatkan risiko dislipidemia maupun penyakit jantung koroner (Konstantyner dkk., 2007).

Penelitian ini menggunakan data primer dan data sekunder sehingga tidak terlepas dari beberapa keterbatasan terkait akurasi data tersebut. Data berat badan ibu sebelum hamil yang diperoleh dari ingatan responden dan data sekunder dari buku KIA/KMS yang terkumpul kemungkinan bukan merupakan berat badan ibu pertrimester yang sebenarnya. Masih kurangnya ibu hamil yang memeriksakan kehamilannya secara lengkap mulai dari trimester I hingga trimester III secara rutin setiap bulan atau trimester. Desain penelitian 
yang digunakan adalah desain penelitian retrospektif, sehingga terdapat kemungkinan terjadinya bias informasi yang didapatkan terutama pada variabel berat badan ibu sebelum hamil. Hal ini disebabkan karena tidak semua ibu yang telah melahirkan masih mengingat berat badan ibu sebelum hamil yang akurat. Selain variabel yang diteliti, masih ada variabel seperti penilaian asupan makanan yang menentukan status gizi, penyakit yang dialami ibu selama hamil dan karakteristik responden yang mungkin dapat berpengaruh lebih dominan terhadap berat lahir bayi.

\section{KESIMPULAN DAN SARAN}

Kami menyimpulkan bahwa ada pengaruh ukuran LILA, berat badan ibu sebelum hamil, pertambahan berat badan Trimester I, pertambahan berat badan Trimester II, pertambahan berat badan Trimester III dengan berat lahir bayi di Puskesmas Kaluku Bodoa tahun 2017-2018. Sehingga didapatkan model prediksi berat lahir bayi berdasarkan faktor-faktor yang mempengaruhi di wilayah kerja Puskesmas Kaluku Bodoa tahun 2017-2018 yang diperoleh $y=1500,435+2,401 X_{1}+7,446 X_{2}$ $+132,484 X_{3}+128,960 X_{4}+103,877 X_{5}$ dimana: $y=$ berat lahir bayi, $X_{1}=$ berat badan ibu sebelum hamil, $\mathrm{X}_{2}=$ ukuran LILA, $\mathrm{X}_{3}=$ pertambahan berat badan trimester I, $\mathrm{X}_{4}=$ pertambahan berat badan trimester II, $\mathrm{X}_{5}=$ pertambahan berat badan trimester III $\left(\mathrm{R}_{2}=\right.$ 80\%) dan semua asumsi regresi linear terpenuhi. Ibu hamil diharapkan lebih peduli dengan kesehatan dan asupan makanan, sebaiknya memeriksakan kesehatan sebelum hamil, selalu memeriksakan kehamilan minimal empat kali terutama lebih peduli terhadap kehamilan pada trimester pertama agar tumbuh kembang janin dapat dipantau sehingga berat lahir bayi dapat optimal, di samping itu memberikan edukasi dan konseling kepada ibu hamil mengenai pentingnya mengontrol berat badan sebelum dan selama kehamilan terutama berat badan ibu sebelum hamil dan pertambahan berat badan trimester pertama, juga mencanangkan program pengetahuan gizi sebelum kehamilan ke dalam materi konseling pernikahan kepada pasangan suami istri yang akan menikah serta mengoptimalkan program pemberian makanan tambahan kepada ibu hamil di trimester pertama lebih diperhatikan.

\section{DAFTAR PUSTAKA}

Brown. (2005). Variation In Newborn Size According To Pregnancy Weight Change ByTrimester 1-3. Am J Clin Nutr 2002;76:205-9. Diakses Tanggal 20 Januari 2017.

Budiman, Riyanto, A., Juhaeriah, J., Gina. (2010). Faktor Ibu yang Berhubungan 
dengan Berat Badan Bayi Lahir di Puskesmas Garuda Tahun 2010. Jurnal Kesehatan Kartika, p. 63-74.

Davis, R. R., Hoffert, S. L., Shenassa, E. D. (2014). Gestational Weight Gain and Risk of Infant Death in the United States. American Journal of Public Health, 104 (1), p. 90- 95.

Dinkes Kota Makassar. (2016). Profil Kesehatan Kota Makassar 2015. Makassar : Dinas Kesehatan Kota Makassar.

Dinkes Prov. Sulsel. (2015). Profil Kesehatan Provinsi Sulawesi Selatan 2014. Makassar: Dinas Kesehatan Provinsi Sulawesi Selatan.

Ferial, E. (2011). Hubungan Antara Status Gizi Ibu berdasarkan Ukuran Lingkar Lengan Atas (LILA) dengan Berat Badan Lahir Bayi di RSUD Daya Kota Makassar. Jurnal Alam dan

Lingkungan, 2 (3), p. 11-21.

Frederick, I. O., Michelle, A. W., Anne, E. S., Diane , P. M., Killien, M. (2008). Prepregnancy Body Mass Index, Gestational Weight Gain, and Other Maternal Characteristics in Relation to Infant Birth Weight. Matern Child Health J, (2008) 12, p. 557-567.

Heerman, W. J., Aihua, B., Shintani, A., Barkin, S. L. (2014). Interaction between Maternal Prepregnancy Body Mass Index and Gestational Weight Gain Shapes Infant Growth. Academic Pediatrics, 14 (5), p.463-370.

Karima, K., Endang, L. A. (2012). Status Gizi Ibu dan Berat Badan Lahir Bayi. Jurnal Kesehatan Masyarakat Nasional, 7 (3), p. 111-119.

Konstantyner, T., Leite, H. P., Taddei, A. C. (2007). Effects Of A Very Low Birth Weight Newborn On Family: Literature Review. Nutricion Hospitalaria, 22 (2), p. 138-145.

Kumar, A., Chaudary, K., Prasad, S. (2010). Maternal Indicators and Obstetric Outcome in the North Indian
Population : A Hospital- Based Study. Journal Of Postgraduate Medicine, 56(3), p.192-205.

Maddah,M.,Karandish, M.,MohammadpourAhranjani, B., Neyestani, TR., Vafa, R., Rashidi, A. (2005). Social Factors and Pregnancy Weight Gain in Relation to Infant Birth Weight: A Study in Public Health Centers in Rasht, Iran. European Journal of Clinical Nutrition, (2005) 59, p. 1208-1212.

Muqsith, A., Putri R, A. (2015). Hubungan Lingkar Lengan Atas Ibu Hamil Dengan Berat Badan Lahir Bayi Di Rumah Sakit Umum Cut Meutia Kabupaten Aceh Utara Dan Rumah Sakit Lhokseumawe Tahun 2015. Jurnal Kedokteran dan Kesehatan Malikussaleh, p.1-7.

Nelson, S. M., Debbie A. L. (2011). Predicting Live Birth, Preterm Delivery, and Low Birth Weight in Infants Born from In Vitro Fertilisation: A Prospective Study of 144,018 Treatment Cycles. PLoS ONE, 8 (1), p.1-11.

Nursusila, Ruslan M., La Ode Ali I. A. (2017). Faktor Risiko Kejadian Berat Badan Lahir Rendah (BBLR) di Rumah Sakit Umum Provinsi Sulawesi Tenggara Tahun 2016. Jurnal Ilmiah Mahasiswa Kesehatan Masyarakat, 2 (6), p. 1-12.

Patki, V. K., Jennifer, V. A. (2017). Maternal Antenatal Profile And Immediate Neonatal Outcome In Very Low Birth Weight Babies. International Journal of Medical Pediatrics and Oncology, 3 (2), p.64-70.

Sari, M., Trini, S. (2013). Model Prediksi Berat Lahir Bayi Berdasarkan Berat Badan Ibu Hamil. Jurnal Kesehatan Masyarakat Nasional, 7 (8), p. 339-343.

Setiati, A. R., Sunarsih, R. (2017). Faktor yang Mempengaruhi Kejadian BBLR (Berat Badan Lahir Rendah) di Ruang Perawatan Intensif Neonatus 
RSUD DR Moewardi di Surakarta.

Jurnal Keperawatan Global, 2 (1), p.920.

Singh, A., Sugandha, A., Harish, C., Aggarwal, K. C., Pandey, R. M. (2014). Prediction Model for Low Birth Weight and its Validation. Indian $J$ Pediatr, 81 (1), p. 24-28.

Stang. (2014). Cara Praktis Penentuan Uji Statistik dalam Penelitian Kesehatan dan Kedokteran. Jakarta : Mitra Wacana Media.

Stang. (2017). Aplikasi Statistik Multivariat dalam Penelitian Kesehatan. Jakarta : Mitra Wacana Media.

Tiro, M. A. (2010). Analisis Korelasi dan Regresi Edisi Ketiga. Makassar : Andira Publisher. 